\title{
The Contribution of Institutional Trust in Determining the Degree of Functional Involvement in Faculty Members and Their Assistants at the Faculty of Physical Education for Girls - Helwan University
}

\author{
Abeer Fathy Mohamed Shaltout ${ }^{1}$ \\ ${ }^{1}$ Assistant Professor, Department of Sports Management and Recreation, Faculty of Physical Education for Girls, Helwan \\ University, Egypt
}

\begin{abstract}
Modern organizations that rely on the ability of the working groups and their harmony to achieve the desired goals adopt institutional confidence and consider it an effective factor in the efficiency and effectiveness of performance, as well as functional absorption is one of the most influential factors in the lives of individuals. The faculty member, when he feels mutual trust in his field of work, accepts his work with great vigor and strives to develop and improve the college and university in which he works. The descriptive methodology was used to suit the nature of the research. The research sample included 150 members of the teaching staff and their assistants at the Faculty of Physical Education for Girls Helwan University. The results of the study showed that the degree of institutional confidence and the degree of functional absorption was high among faculty members and their assistants, as well as a statistically significant correlation between institutional confidence and occupational achievement. Finally, after the confidence of working colleagues from faculty members and their assistants, (Confidence in the head of the scientific department) in determining the degree of functional absorption of faculty members and their assistants, according to the views of the sample of the research.
\end{abstract}

\section{Introduction}

$\mathrm{E}$ ducational institutions are among the most important social, cultural and scientific institutions, and institutional trust is essential.

Modern organizations that rely on the ability of the working groups and their harmony to achieve the desired goals adopt institutional confidence and consider it an effective factor in the efficiency and effectiveness of performance, as well as functional absorption is one of the most influential factors in the lives of individuals.

The faculty member, when she? feels mutual trust in she? field of work, accepts his work with great vigor and strives to develop and improve the college and university in which he works.

In this light, the aim of the research is to identify the contribution of institutional trust in determining the degree of functional involvement of faculty members and their assistants in the Faculty of Physical Education for Girls Helwan University.

The descriptive methodology was used to suit the nature of the research. The research sample included 150 members of the teaching staff and their assistants at the Faculty of Physical Education for Girls - Helwan University. The researcher used as a data collection tool questionnaire (institutional confidence in faculty members and their assistants Faculty and their assistants)

Design by the researcher.

The results of the study showed that the degree of institutional confidence and the degree of functional absorption was high among faculty members and their assistants, as well as a statistically significant correlation between institutional confidence and occupational achievement.

Finally, after the confidence of working colleagues from faculty members and their assistants, (Confidence in the head of the scientific department) in determining the degree of functional absorption of faculty members and 
their assistants, according to the views of the sample of the research.

\section{Search terms:}

Institutional trust - Occupational ingenuity.

\section{Introduction and problem of research:}

Institutional trust is one of the most important institutional variables within the organization. It reflects the overall work environment because of the mutual influence of individuals in the organization. Institutional trust is the basis for the success of universities in achieving high levels of performance.

Confidence in labor relations is one of the basic pillars that help organizations to strengthen their effectiveness and achieve their goals. It is also one of the most effective administrative tools, because it creates the necessary conditions for the success of organizations. (Zahrani 2012)

James (2010) emphasized the importance of institutional trust and its role in institutional integration among the organization's members, ensuring long-term stability and the effectiveness of the institution.

Especially that the modern trend of service organizations requires that the focus in the preservation of human resources for money has a clear impact in increasing performance and achieving continuous successes.

Most studies have shown that there is a positive and moral relationship between trust and performance, and that organizations that operate and their relationship with high levels of trust are more successful, adaptive and creative than organizations that lack trust. (Fleih - 2010)

The faculty member, when he feels the mutual trust between him and the academic leaders and colleagues, accepts his work with great vigor and strives to develop and improve the college and university in which he works. (Ahmad Al-Rasheed - 2015)

Educational institutions are among the most important social, cultural and scientific institutions. They are a network of complex organizations that are constantly changing through their interaction with external structures, and institutional trust is important. (Mohammad Faris 2014)

Modern organizations, which rely on the ability of the working groups to harmonize them to achieve the desired goals, adopt institutional trust and consider it an effective factor in the efficiency and effectiveness of performance.
The subject of functional introspection is one of the important topics that researchers in human resource management have paid attention to recently. (Hazem Kamal Al-Din-2017)

Occupational indulgence is one of the most influential factors in the lives of individuals, especially since the various activities of different organizations and institutions consume a large proportion of the life of the human being. (Emad Alnajjar - 2014)

Individuals who take time to work are positive individuals, interested and enthusiastic in their jobs and are always ready to work extra effort to carry out business in the best possible way and with their full potential. (Al-Abbadi, Jaf2012)

Shilan emphasizes that high-level employees are genuinely and genuinely concerned with their work with greater efficiency and productivity, placing most of their efforts in their work and thus showing the highest performance. (Shilan - 2013)

In view of the importance of human resources as the driving tool for transforming the efforts towards achieving the desired objectives of the educational institution, the university sector is one of the vital sectors that should be taken care of, conducting further studies and research and giving it wide attention.

Based on the recommendations of the previous studies and the researcher's experience as a faculty member, as well as her involvement in academic and administrative work, it has been shown that it is important to study and examine the variables of institutional trust and professional involvement.

In light of this, the current study aims at identifying the contribution of institutional trust in determining the degree of functional involvement of faculty members and their assistants in the Faculty of Physical Education for Girls Helwan University. This helps to achieve the institutional goals set by the college for excellence, achievement and competitiveness in order to maintain quality accreditation and accreditation. One more time.

\section{Search Goal:}

This research aims to identify the contribution of institutional trust in determining the degree of functional involvement of faculty members and their assistants in the Faculty of Physical Education for Girls - Helwan University by identifying the following: 
1- Degree of institutional trust among faculty members and their assistants at the Faculty of Physical Education for Girls - Helwan University.

2 - Degree of functional absorption of faculty members and their assistants at the Faculty of Physical Education for Girls - Helwan University.

3 - The relationship between institutional trust and professional indulgence among faculty members and their assistants at the Faculty of Physical Education for Girls Helwan University.

4- The percentage of the contribution of the dimensions of institutional confidence in determining the degree of functional involvement of faculty members and their assistants at the Faculty of Physical Education for Girls Helwan University.

\section{Search questions:}

1 - What is the degree of institutional trust among faculty members and their assistants at the Faculty of Physical Education for Girls - Helwan University?

2- What is the degree of professional involvement of faculty members and their assistants at the Faculty of Physical Education for Girls - Helwan University?

3- Is there a statistically significant correlation between the institutional trust and the professional involvement of faculty members and their assistants in the Faculty of Physical Education for Girls - Helwan University?

4 - What percentage of the contribution of the dimensions of institutional confidence in determining the degree of functional absorption of faculty members and their assistants at the Faculty of Physical Education for Girls Helwan University?

\section{Terminology:}

\section{Institutional Trust}

Mohamed Hamza, quoting Ladebo (2017), defined "feelings of acceptance, persuasion, and lack of fear, doubt, and hesitation when one deals with others (colleagues - direct president - senior management) together with the willingness to rely on them."

Al-Ta'i (2007) defined "the individual's faith in the goals, decisions, policies, organization and organization of all individuals working in the organization, reflecting the individual's satisfaction and commitment to the organization."
The researcher is concerned that the institutional trust is the trust of the faculty member - their assistants with the policies of (senior management - direct president colleagues) and the conviction of dealing and interdependence with them to reach the college of competitive advantage.

\section{Job Involvement:}

Jaid (2012) defined "the positive attitude and feeling of the workers in achieving the goals and values of the organization".

While Shilan (2013) defined it as "the degree to which the individual integrates with the job, this post is a pivotal dimension in his life and self-esteem, influenced by the degree of his performance."

In this study, the researcher is concerned that the occupational absorption is the extent to which the faculty member's involvement and the integration of the faculty members with a positive role in their achievement reflected the enthusiasm and pride of his job in order to achieve the objectives of the college.

\section{Research Methodology:}

The researcher used the statistical descriptive method of survey studies in conducting this study for the nature of this research, which describes what is being.

\section{Community and Sample Search:}

The total number of faculty members and their assistants from the research community was chosen in order to conduct the study. (174) of the faculty members and their assistants, and the number of (24) form was excluded for non-completion. Thus, the actual sample (150) of the faculty members and their assistants.

\section{Data collection tools:}

- The researcher used two questionnaires as a tool for collecting data according to the following:

A - Access to specialized scientific references in the field of research problem, as well as studies related to the subject of the current study.

B- In the light of the results of what was reached, the questionnaire forms were constructed as follows:

The first questionnaire: institutional trust among faculty members and their assistants:

1 - The researcher determined the dimensions of the questionnaire as well as wording of the terms that cover the dimensions of the questionnaire. 
2. The questionnaire was presented to a group of experts (Annex 1) in its initial form (a). It included three dimensions (52 words) (Annex 2) for their review, from $12 / 2 / 2018$ to $25 / 2 / 2008$. $2018 \mathrm{~m}$.

3. All experts agreed on the dimensions of the questionnaire. The researcher also agreed that $80 \%$ or more of the experts' opinions on the questionnaire should be accepted (Appendix 3).

4. Through the opinions of the experts on the relevance of the questionnaire, the words $(6,11,15)$ were deleted from the first dimension, "confidence in higher management." The words $(10,11,13)$ were deleted from the second dimension "trust in the head of the scientific department" $(4,10,12,14,15,16)$ from the third dimension, "Trust in fellow faculty members and their assistants".

5- I have a five-point scale that I strongly agree $=5$, I agree $=4$, I agree somewhat $=3$, I disagree $=2$, I strongly disagree $=1$ degree.

6- The pilot study of the questionnaire form in its initial form (B) (Appendix 4) was applied to a sample of (50) faculty members and their assistants from the research community and not from the sample under study in the period from $4 / 3 / 2018$ to $15 / 3 / 2018$. .

The Second Questionnaire: Employment of faculty members and their assistants:

1 - The researcher determined the dimensions of the questionnaire as well as wording of the terms that cover the dimensions of the questionnaire.

2. The questionnaire was presented to a group of experts (Annex 1) in its initial form (a), which included three dimensions (26 words) (Annex 2) for their review, from $12 / 2 / 2018$ to $25 / 2 / 1427$. $2018 \mathrm{~m}$.

3. All experts agreed on the dimensions of the questionnaire. The researcher also agreed that $80 \%$ or more of the experts' opinions on the questionnaire should be accepted (Appendix 3).

4. Through the opinions of experts on the relevance of the questionnaire expressions, the words $(5,6)$ of the first dimension were removed from the first dimension, "Cognitive-cognitive introspection," and the second term, "emotional-emotional absorption," was deleted. $(7,8)$ of the third dimension, "physical-physical absorption", and the number of expressions of questionnaire (21) is a phrase.

5- I have a five-point scale that I strongly agree $=5$, I agree $=4$, I agree somewhat $=3$, I disagree $=2$, I strongly disagree $=1$ degree.

6- The pilot study of the questionnaire form in its initial form (B) (Appendix 4) was applied to a sample of (50) faculty members and their assistants from the research community and not from the sample under study in the period from $4 / 3 / 2018$ to $15 / 3 / 2018$. .

Basic Study:

The researcher applied the questionnaire forms (the institutional trust of the faculty members and their assistants, the professional involvement of faculty members and their assistants) in its final form (Appendix 5 ) to the members of the research sample of faculty members and their assistants - ) After confirming the validity and consistency of the questionnaire forms and the exclusion of (24) form for non-completion, has been the implementation procedure in the period from $21 / 3 / 2018$ to 24/4/2018.

\section{View and discuss the results:}

The following is the presentation and discussion of the results and their interpretation in the light of the answer to the research questions through the theoretical framework for research, studies and reference studies.

Table (1)

Arithmetical mean, standard deviation and torsion coefficient of sample responses on the dimensions of the institutional confidence questionnaire under study $(n=150)$

\begin{tabular}{|c|c|c|c|c|}
\hline Serial & Dimension & M & $\mathbf{E}$ & $\mathbf{L}$ \\
\hline 1 & Trust in Senior Management (Dean - Agents) & 45.49 & 10.39 & $0.814-$ \\
\hline 2 & Trust in the head of the scientific department & 56.73 & 10.62 & $0.796-$ \\
\hline \multirow[t]{2}{*}{3} & Trust in colleagues (faculty members and their assistants) & 56.58 & 10.98 & $0.453-$ \\
\hline & Total degree & 158.80 & 27.57 & 0.592 \\
\hline
\end{tabular}

Table (1) shows that:

The values of the arithmetic averages of the responses of the research sample varied on the dimensions of the institutional confidence questionnaire among the faculty members and their assistants. The torsion coefficient was limited to $(+3,-3)$ indicating the moderation of the data.

Table (2) shows that the arithmetic average of the confidence interval of the head of the scientific department 
was the highest of 56.73, while the confidence of the colleagues in the second ranking reached (56.58) (45.49). This indicates that the trust of the head of the scientific department is the most important dimension of the institutional trust among faculty members and their assistants. It was found that a large percentage of the heads of the scientific departments enjoy the acceptance of faculty members and their assistants, In the high degree of confidence in the head of the department For a scientific result of the adoption of those presidents style wise leadership.

The researcher attributed that the distinction of the head of the scientific department of the Faculty of Physical Education for Girls - Helwan University with a high degree of institutional confidence that it is due to the extent of the recognition of the research sample from the faculty members and their assistants to the manner of management of the work team in the scientific section and the spirit of working as a team among them and confidence in their abilities and encourage their efforts and distribution of competencies and tasks Work fairly, as well as his interest in human relations and other achievements and administrative and academic commitment.

This was confirmed by Falih (2010) on the supervisor gaining the confidence of subordinates if they have the facts of competence, merit, ethics and openness to subordinates and attention to their interests and needs and support, and justice in dealing with them.

According to Mabrouka Al-Khafee (2017), providing institutional confidence in the direct president helps to increase the degree of institutional loyalty among the employees, which contributes to increasing productive efficiency.

The results of the study of Amira Kazem (2014), Mohammad Faris (2014), Nasreen Abu Shawish (2013) and Hamad Bin Salman (2010) show that the difference with the current study is the second place among the dimensions of institutional trust.
It is also noted from Table (9) that the total degree of institutional confidence is (158.80). This indicates that the degree of institutional trust in the members of the research sample of faculty members and their assistants at the Faculty of Physical Education for Girls - Helwan University is high because this degree is limited to (148) 200) as a sign of the high degree of institutional trust.

The researcher attributed this to the fact that the members of the research sample are distinguished from faculty members and their assistants in their acceptance of the objectives of the college and the university and the desire to continue to achieve quality and excellence in the institutional work, which is reflected in their performance and high degree of institutional trust in the head of the scientific department and colleagues and senior management.

Najwa Darawshe's study (2017) also confirms that trust is an important element in achieving university goals as faculty members who are confident about their university are more willing to succeed in creating productive learning environments.

The results of Mohamed Fares (2014) study show that educational institutions are among the most important social, cultural and scientific institutions, and that there is a need for positive institutional trust as a fertile environment for the growth of human thought.

The results of this study are consistent with the results of the study of Ahmad Hamdan (2017), Muhammad Hamza (2017), Najwa Darawshe (2017), Ahmed Al-Rashidi (2015) and Amira Kazem (2014) High of institutional trust.

The results of this study differed with the results of the study of Awnia Abo sinina (2015) that the degree of institutional confidence was medium.

The results obtained from Table (1) answer the first question, which states: "What is the degree of institutional trust in faculty members and their assistants at the Faculty of Physical Education for Girls - Helwan University?"

Table (2)

The arithmetic mean, standard deviation, and torsion factor of the sample responses to the dimensions of the functional inference questionnaire are under study $(\mathbf{N}=150)$

\begin{tabular}{|c|c|c|c|c|}
\hline Serial & Dimension & M & E & L \\
\hline $\mathbf{1}$ & Cognitive Acquisition - Perception & 30.98 & 3.52 & 0.918 \\
\hline $\mathbf{2}$ & Emotional absorption - emotional & 33.68 & 5.31 & $1.13-$ \\
\hline $\mathbf{3}$ & Physical - material absorption & 27.34 & 2.97 & $1.32-$ \\
\hline & Total degree & 92.0 & 10.55 & 1.10 \\
\hline
\end{tabular}

Table (2) shows that: 
The values of the arithmetic averages of the responses of the research sample differed on the dimensions of the functional introspection questionnaire among the faculty members and their assistants. The torsion coefficient was limited to $(+3,-3)$ indicating the moderation of the data.

Note from Table (10) that the arithmetic average of the emotional-affective dimension was the highest of 33.68, followed by cognitive-cognitive attainment in the second order, where the arithmetic mean was 30.98 , and after physical- (27.34). This indicates that the emotional and emotional absorption of the faculty members and their assistants is the most important dimension of professional involvement. It is understood by the faculty members and their assistants, where there is a strong relationship between the thoughts and feelings of the faculty member and his work tasks, leading to his enthusiasm and passion As well as a sense of satisfaction with success in doing business.

The researcher attributed this to the recognition of the research sample from faculty members and their assistants to develop their ethical behaviors and their vitality and enthusiasm in performance and stability during the pressures of work and difficulties, as well as increasing their respect for the college administration. This leads to the continuation of success and achievement of excellence for the educational institution "college" through renewed accreditation for quality.

This is confirmed by Men (2012): "The good feelings of employees towards their organizations such as admiration, emotional attractiveness and confidence will make them more willing to work and attention to institutional activities, and this will contribute to the absorption of workers in their jobs."

Muhammad Gad Al-Karim (2017) points out: "To the workers' sense of self-esteem and to express themselves through the performance of their duties."

The results of the study of Hazem Kamal Al-Din (2017) and Mohammad Gad Al-Karim (2017) showed differences with the current study in obtaining after physical absorption in the first order of the dimensions of occupational absorption.

It is also noted from Table (10) that the total degree of occupational absorption is (92.0). This indicates that the degree of occupational absorption of the members of the research sample from faculty members and their assistants at the Faculty of Physical Education for Girls - Helwan University is high because this degree is limited to (78) 105 ) as a sign of the high degree of functional exhaustion.

The researcher attributed this to the fact that the members of the research sample distinguished faculty members and their assistants to meet the challenges of the work correctly and provide them with information and knowledge and give them the opportunity to identify their work and participate in the decision-making process and their feeling that they are an integral part of the college and pride in their job and to do their best capacity and ability to accomplish their work better Which is reflected more in raising the level of their employment.

According to Mohammed Bakri Abdul Alim (2012), "Occupational immersion is an important feature of institutional life and the basis for access to institutional effectiveness and positive feedback from employees."

Thus, the study of Shilan Fadel (2013) notes that "individuals with high levels of professional involvement are genuinely and genuinely concerned with their work with greater efficiency and productivity, placing most of their efforts in their work and thus showing higher performance."

The result of this study is consistent with the results of the study of Ahmed Ibrahim (2017), Iman Nassar (2013) in determining the degree of occupational absorption through the responses of members of the research sample to a high degree.

The results of this study differed with the results of the Zaid Abdullah study (2018) in determining the degree of functional immersion in a medium degree.

The result of this study was also contradicted by the study of Noha Abdel Razek (2015) in determining the level of functional immersion at a low level.

The results obtained from Table (2) answer the second question, which states: "What is the degree of functional absorption of faculty members and their assistants in the Faculty of Physical Education for Girls - Helwan University?" 
Table (3)

Link values between institutional confidence dimensions And the degree of dimensions of functional absorption of faculty members and their assistants $(N=150)$

\begin{tabular}{|c|c|c|c|}
\hline $\begin{array}{c}\text { Occupational indulgence } \\
\text { Institutional trust }\end{array}$ & $\begin{array}{c}\text { Cognitive - perception } \\
\text { absorption }\end{array}$ & $\begin{array}{c}\text { Emotional absorption - } \\
\text { emotional }\end{array}$ & $\begin{array}{c}\text { Thysical - material } \\
\text { absorption } \\
\text { degree }\end{array}$ \\
\hline $\begin{array}{c}\text { Trust in Senior Management (Dean - } \\
\text { Agents) }\end{array}$ & $0.395^{*}$ & $0.357^{*}$ & $0.346^{*}$ \\
\hline $\begin{array}{c}\text { Trust in the head of the scientific } \\
\text { department }\end{array}$ & $0.458^{*}$ & $0.461^{*}$ \\
\hline $\begin{array}{c}\text { Trust colleagues from faculty and } \\
\text { their staff }\end{array}$ & $0.420^{*}$ & $0.463^{*}$ \\
\hline Total degree & $0.493^{*}$ & $0.511^{*}$ & $0.225^{*}$ \\
\hline
\end{tabular}

* Value (t) of the table $=(0.174)$

Table (3) shows that:

There is a statistically significant correlation between the degree of institutional confidence dimensions and the degree of dimensions of functional absorption as well as the total score for them.

Table (4)

Multiple linear regression analysis of the contribution ratio Dimensions of Institutional Confidence in Occupational Exclusion $(\mathrm{N}=150)$

\begin{tabular}{|c|c|c|c|c|c|c|}
\hline \multirow{2}{*}{ Step } & \multirow{2}{*}{$\begin{array}{c}\text { Fixed } \\
\text { amount }\end{array}$} & \multirow{2}{*}{$\begin{array}{c}\text { Standard } \\
\text { error }\end{array}$} & \multirow{2}{*}{$\mathbf{F}$} & $\begin{array}{c}\text { Trust colleagues from faculty and } \\
\text { their staff }\end{array}$ & $\begin{array}{c}\text { Trust in the head of the scientific } \\
\text { department }\end{array}$ & $\begin{array}{c}\text { Contribution } \\
\text { Ratio }\end{array}$ \\
\hline $\mathbf{1}$ & 63.92 & 9.05 & 72.07 & 0.496 & - & 51.7 \\
\hline $\mathbf{2}$ & 59.66 & 8.92 & 40.59 & 0.360 & 0.211 & 54.0 \\
\hline
\end{tabular}

Table (4) shows that:

The variables contributing to the achievement of (Occupational Involvement) among faculty members came in first place (confidence in colleagues from faculty members and their assistants) by (51.7\%) followed by (confidence in the head of the scientific department) by $(2.3 \%)$ :

$\mathrm{Y}=\mathrm{a}+\mathrm{b} 1 \mathrm{x} 1+\mathrm{b} 2 \neg \mathrm{x} 2$

Occupational Involvement $=59.66+(0.360 \times$ confidence in colleagues $)+(0.211 \times$ Head of Section $)$

It is noted from Table $(4,5)$ in light of the response of the sample of the research: There is a statistically significant correlation between the degree of the dimensions of the institutional confidence and the degree of the dimensions of functional introspection as well as the total score for them. (Confidence in the head of the scientific department). It is clear from this the contribution of the dimensions of institutional confidence in determining the degree of occupational absorption among faculty members and their assistants at the Faculty of Physical Education for Girls - Helwan University.

This means that the greater the degree of institutional trust in faculty members and their assistants, the greater the degree of professional involvement of faculty members and their assistants.

The researcher points out that institutional trust is one of the main pillars of organizations and institutions, especially educational institutions. It is considered an important factor in the success of the educational institution to keep abreast of the changes and developments in achieving institutional excellence. The faculty member achieves sufficient institutional trust in senior management, head of scientific department and colleagues.

Whenever it is linked to his place of work and whenever he has the maximum efforts to engage in work to raise the status of the College, and in view of the absorption of the job and the gains made for the benefit of the whole system, the corner reservation is the members of the body To teach and their assistants who are among them and start the college towards achieving competitive advantage.

Najwa Darawshe (2017) emphasizes in her study that "the individual's sense of confidence and belonging to his institution is not easy. It is a complex process, because of its direct connection with human behavior and dealing with many human self-variables in order to satisfy its needs related to the internal and external circumstances of the individual." 
The study of Ahmed Madi (2014) points out that "the importance of occupational absorption lies in the fact that it is at the heart of the functional relationship, because it deals with what individuals do and how they act in their roles and what makes them behave in other ways to achieve both the goals of the organization and their personal goals".

The results of this study are consistent with the results of the study of Mohammed Hamza (2017), Najwa Darawshe (2017), Ahmed Rashidi (2015), Mika Vanhala (2016), Fabian Ougwu (2014) With statistically significant correlation.

The results of this study are also consistent with the results of the study of Zaid Abdullah Zeid (2018), Ahmed Ibrahim (2017), Hazem Kamal Al-Din (2017), Mohammad Gad Al-Karim (2017), Iman Nassar , Ho, Chin-Chin (2012) through the relationship of functional estrangement with different variables with a statistically significant correlation.

The results from Table $(11,12)$ respond to the third and fourth questions, which state: "Is there a statistically significant correlation between the institutional trust and the professional involvement of faculty members and their assistants in the Faculty of Physical Education for Girls Helwan University? Degree of occupational absorption of faculty members and their assistants at the Faculty of Physical Education for Girls - Helwan University?

\section{Results:}

\section{The researcher reached the following results:}

1- Degree of institutional trust among faculty members and their assistants at the Faculty of Physical Education for Girls - Helwan University - high degree.

2 - degree of occupational absorption of faculty members and their assistants at the Faculty of Physical Education for Girls - Helwan University - high degree.

3 - The existence of a statistical correlation between statistical and institutional confidence in faculty members and their assistants in the Faculty of Physical Education for Girls - Helwan University.

4 - Obtained after (confidence in the colleagues of the faculty members and their assistants) the highest contribution rate and then in the proportion of the contribution after (confidence in the head of the scientific department) to the dimensions of institutional confidence in determining the degree of occupational absorption of faculty members and their assistants at the Faculty of
Physical Education for Girls - Helwan University According to the views of the research sample.

\section{Recommendations:}

Within the limits of the research sample and its procedures based on the results reached, the researcher recommends the following:

1 - Strengthening the values of both institutional trust and functional arrogance as important elements in achieving the goals of universities.

2 - Increase the attention of senior management faculty (Dean - agents) members of the faculty and their assistants and create an appropriate regulatory environment to ensure the continued success of the work.

3 - Work to remove the negative effects of personal relationships at work, and focus on the positive relations.

4 - the use of modern and appropriate management methods to increase the spirit of cooperation and work groups and the dissemination of trust among them, which reflects on the absorption of the job positively.

\section{References}

1 - Ahmed bin Hassan Al-Wazzab Al-Zahrani (2012): "Institutional trust with the directors of secondary schools in Taif and its relationship to creative administrative behavior", Master Thesis, Umm Al-Qura University, Saudi Arabia, p.

2- Ahmed Deeb Mohammed Madi (2014): "The impact of institutional support on the development of occupational absorption in the staff of the Gaza Regional Office of UNRWA", Master Thesis, Faculty of Commerce, Department of Business Administration, Islamic University, Gaza.

3 - Ahmed Hamdan Barhoum (2017): "the reality of institutional trust in secondary schools in Rafah," Journal of Palestine University for Research and Studies, Volume (7), No. (2).

4 - Ahmed Ibrahim Musa (2017): "The Effect of Psychological Empowerment of Workers on the Level of Functional Obsession - An Empirical Study on the Directorate of Youth and Sports in Menoufia Governorate", Journal of Commercial Research, Faculty of Commerce, Menoufia University,Number (2).

5- Ahmed Obeid Sweid, Al-Rashidi Assistant (2015): "The degree of institutional trust in Kuwait's public and private universities and their relation to motivation among 
faculty members from their point of view", $\mathrm{PhD}$ Thesis, Faculty of Education, Yarmouk University, Jordan, p.

6- Ali Razaq Jiyad (2012): "Institutional agility is a strategic entry in the process of enhancing the employment of the workers - a pilot study of a sample of industrial sector companies in the Ministry of Industry and Minerals", Al-Ghari Journal of Economic and Administrative Sciences, (24).

7. Amira Khudair Kazem (2014): "institutional trust and its role in enhancing institutional loyalty - an applied study for a number of employees in the branches of Rafidain Bank in Najaf Al-Ashraf, Al-Ghari Journal of Economic and Administrative Sciences, Volume (8) P. 234.

8-Fabian ougwu, "Linking organizational trust with employee engagement; the role of psychological empowerment", Personnel Review, 43 (3), 2014, pp. 377 400 .

9- Hamad bin Sulaiman Al-Badrani (2010): "Understanding institutional justice and its relation to trust in security organizations", PhD thesis, Department of Administrative Sciences, College of Graduate Studies, Naif Arab University for Security Sciences, Riyadh.

10- Hashim Fawzi Al-Abbadi, Walaa Jawdat Al-Jaf (2012): "Strategies for Enhancing Employment Intolerance and its Role in Achieving the High Performance of Business Organizations: An Exploratory Study of a Sample of Employees in the Iraqi Banking Sector in Arbil", Journal of College of Administration and Economics, ), No. 9, p. 79.

11- Hikmat Mohamed Falih (2010): "Analysis of the Relationship between Institutional Trust and Institutional Commitment - A Survey Study in the Retirement and Social Care Departments in Tikrit City", Journal of Management and Economics, Mustansiriya University, No. 83, p.

12-Ho, Chin-Chin and Oldenburg, Brian and Day, Gary and Sun, Jing, "Work Values, Job Involvement, and organizational commitment in Taiwanese Nurses", International Psychology and Behavioral Sciences, Vol. 2, No. 3, 2012, pp. 64-70.

13. Imad Abdul Aziz Al-Qasabi Al-Najjar (2014): "The role of internal work environment factors in the development of occupational absorption", Journal of Commercial Studies and Environmental Research, Vol. (5), No. (2), p.
14- Iman Hassan Gomaa Nassar (2013): "Quality of Work Life and its Impact on the Development of Occupational Achievement", Master Thesis, Faculty of Commerce, Islamic University, Gaza.

15-Iman Hassan Gomaa Nassar (2017): "Occupational Inheritance and its Relation to the Level of Achievement among Workers in Youth Care Departments at Asyut University", Asyut Journal of Physical Education Sciences and Arts, Egypt, No. 45, 72.

16--James, H., "A Study organizational trust and related variable Among faculty members at HBUCS", unpublished Ph.D. Dissertation. The University of Iowa, IOWA. 2010.

17--Linjuan Rita Men, CEO Credibility, Perceived organizational reputation, and employee engagement, public relations review, 38, 2012, pp. 171-173.

18- Mabrouka Abdulla Al-Khafaki (2017): "Role of strategic leadership practice in enhancing institutional confidence in Libyan industrial organizations", Libyan International Journal, Faculty of Education, University of Benghazi, No. 26.

19-Mika Vanhala, "Orgonizational Trust dimensions as antecedents of organizational commitment", Knowledge and process Management, 23 (1), 2016, p.p. 46-61.

20- Mohamed Bakry Abdel-Alim (2012): "Determinants and Dimensions of Institutional Justice and its Impact on Functional Exclusion (Applied Study), New Horizons for Commercial Studies, Egypt, Vol. (24), Issue (2).

21- Mohamed Gad Al-Kareem Obaid Ali (2017): "Types of Administrative Leadership and its Relation to Occupational Exploitation among Workers in Youth Care Departments, Asyut University", Master Thesis, Faculty of Physical Education, Asyut University.

22 - Mohamed Hamza Amin Abdullah (2017): "institutional trust and occupational indulgence - field study Beni Suef University, Journal of the Faculty of Arts, Tanta University, Egypt.

23- Mohammed Jawdat Mohammed Fares (2014): "The Relationship between Institutional Trust and Institutional Commitment - A Field Study on Al-Azhar University Gaza", Journal of the Islamic University for Economic and Administrative Studies, vol. 22, no. 2, p.

24 - Najwa Darawshe (2017): "The Institutional Justice prevailing in Jordanian Universities and their Relation to Institutional Confidence from the Point of View of Faculty Members", Jordanian Journal of Educational Sciences, Volume (13), (3). 
25- Nisreen Ghanem Abdullah Abu Shawish (2013): "Determinants of Institutional Confidence and its Effects An Empirical Study on UNRWA Personnel", Master Thesis, Department of Business Administration, Faculty of Commerce, Islamic University, Gaza.

26. Noha Abdel-Razek El-Sherbini (2015): "The Impact of Transformational Leadership on Occupational Observation", Journal of Business and Environmental Studies, Egypt, Vol. (6), Issue (1).

27 - Rasha Nasser Al-Tai (2007): "Leadership styles and institutional confidence and their impact on achieving institutional commitment - an applied study of the views of a sample of trainers in companies of mixed industrial sector", unpublished master thesis, Faculty of Management and Economics, University of Baghdad.
28- Shilan Fadel Mahmoud (2013): "The Role of Some Human Engineering Factors in Functional Observation - A Survey Study of the Opinions of a Sample of the Employees of Asia Cell Communications Company", Master Thesis, Faculty of Management and Economics, University of Salmaniya, p. 79.

29- Talib Abu Sneina (2015): "The level of institutional trust in the general secondary schools in Jerash from the point of view of teachers", Al-Quds Open University Journal for Research and Educational and Psychological Studies, Volume (4), No. (14).

30- Zaid Abdullah Zeid Al-Olayan (2018): "Regulatory Health in Secondary Schools and its Relation to the Occupational Exploitation of Teachers in the State of Kuwait", Master Thesis, Faculty of Educational Sciences, Al-Bayt University, Jordan. 